\title{
Influence of Density and Water Content on The Thermal Diffusivity of Wood Chips
}

\author{
Oussama Zine ${ }^{1 *}$, Abdelmajid El bouardi ${ }^{1}$, Driss Taoukil ${ }^{1}$, El-Hadj Kadri $^{2}$, Ikram El abbassi ${ }^{3}$ \\ ${ }^{1}$ Energetic Laboratory, Physics Department, Faculty of Sciences Tetouan, Abdelmalek Essaadi University, Morocco \\ ${ }^{2}$ Laboratory L2MGC, CY Cergy Paris University, 95000 Cegy-Pontoise, France \\ ${ }^{3}$ ECAM EPMI, 3 Boulevard de l'Hautil, Cergy-Pontoise, 95052, France
}

\begin{abstract}
The use of agro-industrial residues are currently experiencing an undeniable revival of interest in developing fully renewable insulation materials, that can be competitive in price and performance, in addition of low embodied energy. Among these vegetable waste materials; wood chips. These latter are light, compressible and very sensitive to water, due to their highly porous structure, which constantly modifies their thermal properties. The main objective of this study is to examine the influence of moisture content and density on the thermal diffusivity of wood chips, using the flash method. Four theoretical models were used to identify the thermal diffusivity. The results obtained show a decrease in thermal diffusivity with an increase in wood chips density. Furthermore, moisture content has an influence on thermal diffusivity. The experimental results show fluctuations with a slight decrease in thermal diffusivity with a maximum corresponding to a moisture content value $\mathrm{W}_{\mathrm{m}}$.
\end{abstract}




\section{Nomenclature}

$\begin{array}{ll}\rho_{\text {app }} & \text { Apparent density }\left(\mathrm{kg} / \mathrm{m}^{3}\right) \\ \mathrm{M} & \text { Mass }(\mathrm{kg}) \\ \mathrm{V} & \text { Volume }\left(\mathrm{m}^{3}\right) \\ \mathrm{W} & \text { Water content }(\%) \\ \mathrm{M}_{\mathrm{h}} & \text { Wet mass }(\mathrm{kg}) \\ \mathrm{M}_{\mathrm{d}} & \text { Dry mass }(\mathrm{kg}) \\ \alpha & \text { Thermal diffusivity }\left(\mathrm{m}^{2} / \mathrm{s}\right) \\ \mathrm{e} & \text { Thickness }(\mathrm{m}) \\ \mathrm{t} & \text { Time }(\mathrm{s}) \\ \mathrm{T} & \text { Temperature }(\mathrm{K}) \\ \mathrm{M}_{0} & \text { Partial moment of order } 0 \\ \mathrm{M}_{-1} & \text { Partial moment of order }-1 \\ \mathrm{t}_{0} & \text { The duration of excitation }(\mathrm{s}) \\ \rho & \text { Density }\left(\mathrm{kg} / \mathrm{m}^{3}\right) \\ \mathrm{k} & \text { Thermal conductivity }(\mathrm{W} / \mathrm{mK}) \\ \mathrm{C}_{\mathrm{p}} & \text { Specific heat capacity }(\mathrm{J} / \mathrm{kgK})\end{array}$

\section{Introduction}

Nowadays, there is growing interest in the use of sustainable materials in building envelopes, due to their many advantages, such as their ecological character, biodegradability, the origin of renewable resources, and their capacity to cause much less pollution during their production stage. This, reduces the building's embodied energy and allows for significant energy savings. The use of bio-sourced materials contributes to a sustainable development approach. Unlike some materials that are generally obtained from nonrenewable resources, such as polymers based or from natural sources, like glass or rock wool, which require high energy during their production stage. This means more $\mathrm{CO} 2$ released into the atmosphere. As well as, problems in their disposal process, in reusing or recycling the products at the end of their lives [1].

The problem of agro-industrial waste disposal in developed countries has created opportunities to develop these wastes and produce new local materials that can be competitive in price and performance. Notably, in building envelopes, as insulating panels or by mixing with a certain type of binders to improve their thermal, even if acoustic, performance. This will respond to the concern for saving natural resources and the obligation to limit the deposit of waste on the ground.

Some of these materials have been used in several studies, they have shown good thermal performance compared to conventional insulation materials [2]-[5]. Indeed, the addition of these plant aggregates in the binder matrix leads to a linear decrease in thermal conductivity. This is directly related to the density of the materials. In fact, these natural materials have shown a high sensitivity to moisture, due to their porous structure, which leads to a high sorption/desorption capacity of the water content in their surrounding environment. This, has been explained from the experimental study of dynamic vapor sorption by Palumbo et al. [6] on two types of bio-sourced materials. Similar studies were utilized for hemp-lime, straw-strach, corn pith alginate and wood wool, these latter corresponds to high and good moisture buffering capacity. In addition, this hygroscopicity can influence their thermal properties [7]. The same conclusion has been shown by Taoukil et al. [8] in which the water content modifies the thermophysical characteristics of the wood concrete.

The residues from the wood processing industry are part of the vegetable aggregates, made from renewable materials and are widely available around the world. They fill an important place in thermal insulation due to their interesting characteristics, including porosity, which makes it lightweight and compressible. Its behavior, therefore, differs from that of conventional rigid aggregates. The research conducted by Vololonirina et al. [9] on three types of wood-based materials showed that their thermal conductivity increase linearly with temperature, and since they're also sensitive to water like other natural plant origin materials, they showed a linear increase in thermal conductivity as a function of water content.

The aim of this paper was to study the effect of density value, and the water content ratio on thermal diffusivity of wood chips without any additional binder, knowing that the thermal diffusivity characterizes the ability of a material to diffuse heat. Thus, It is an important property when considering unsteady state heat transfer situations.

\section{Material and experimental study}

\subsection{Material : Wood chips}

The wood residues used in this study are wood chips (Fig.1). They are industrial waste from the sawmill industry. They were chosen for their availability in woodworking activities around the world. These chips have created as a result of machine tool machining of a raw material to obtain a residue of parallelepiped shape, with different particle sizes that vary between 5 and $30 \mathrm{~mm}$ depending on the particle size analysis.

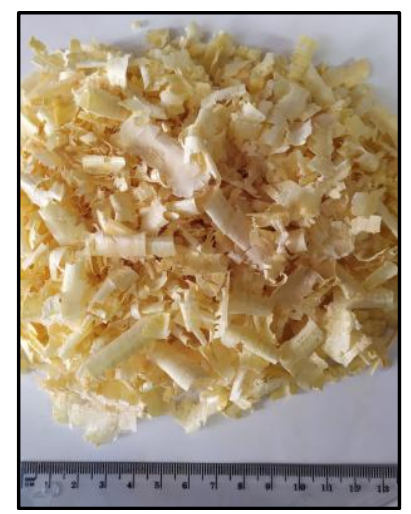

Fig. 1. Wood chips 


\subsection{Experimental study}

\subsubsection{Bulk density}

The bulk density was measured in a parallelepiped frame, this frame is filled with a quantity of aggregates and then weighted.

The degree of compaction giving rise to a different density, starting with the first filling where the wood chips are poured into the frame without any compaction, and the other fillings were exposed this time to a progressive increase in the degree of compaction using a compressive press machine, by introducing more mass with keeping the same volume. The value obtained is substituted in the equation.1, where $\mathrm{M}$ defined by the mass of the particles divided by the apparent volume $\mathrm{V}$ they occupy:

$$
\rho_{\text {app }}=\frac{M}{V} .
$$

\subsubsection{Water content}

The plant particles were previously steamed at $100^{\circ} \mathrm{C}$ for 24 hours, afterwards they were immersed in water, and the masse gain over time was obtained.

From these values, the percentage mass gain was measured as the mass gain divided by the dry mass of the wood chips:

$$
W_{t}(\%)=\frac{M_{h}(t)-M_{d}}{M_{d}} \times 100
$$

\subsubsection{Thermal diffusivity}

The thermal diffusivity of wood chips as a function of density and water content was measured in the transition regime using the flash method. This method (fig.2) consists of exciting the sample on its front face by a uniformly distributed pulse flux, often using a 1000 watts power incandescent lamp, and in measuring the temporal evolution of the temperature using a thermocouple, which receives the flow coming from the back face of the sample (opposite face to the one receiving the pulse), from which the average temperature on the back face is deduced.

The excitation flux is totally absorbed by the sample on the front face, due to its reflected internal walls. The excitation duration used is 20 seconds. Indeed, this duration is sufficient to obtain an elevation significant backside temperature.

The analysis of the experimental thermogram recorded in the non-irradiated side allows to determine the thermal diffusivity of the sample, using already existing models, which are based on the knowledge of analytical solutions of the transient thermal field, sometimes, in specimens of known geometry with initial and boundary conditions.

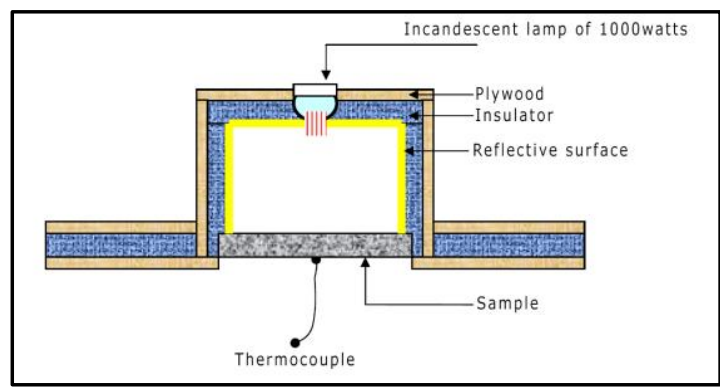

Fig. 2. Flash method

In this study, four models were used to determine the thermal diffusivity of a material (Parker, Degiovanni, Degiovanni and Laurent, Yezou). Subsequently, the diffusivity values determined by these models are compared.

Parker's model [10] assumes that the sample is cylindrical and perfectly insulated, i.e. heat losses are neglected, due to the short excitation time. The material is also assumed to be homogeneous, isotropic and opaque.

Parker determines the diffusivity from a point that corresponds to the half elevation of the maximum temperature $1 / 2=\Delta \mathrm{T}(\mathrm{e}, \mathrm{t} 1 / 2) / \Delta \mathrm{T} \max$.

Thermal diffusivity is then determined from the relation:

$$
\alpha=0,139 \frac{e^{2}}{t_{1 / 2}}
$$

Degiovanni's model [11] takes into account the thermal losses. It has considered several couples of points, at the characteristics times $\mathrm{t}_{1 / 3}, \mathrm{t}_{1 / 2}, \mathrm{t}_{2 / 3}, \mathrm{t}_{5 / 6}$ presented:

$$
\begin{aligned}
& \alpha_{2 / 3}=e^{2} \frac{\left(1,150 t_{5 / 6}-1,250 t_{2 / 3}\right)}{t_{5 / 6}{ }^{2}} \\
& \alpha_{1 / 2}=e^{2} \frac{\left(0,761 t_{5 / 6-0} 0,926 t_{1 / 2}\right)}{t_{5 / 6}{ }^{2}} \\
& \alpha_{1 / 3}=e^{2} \frac{\left(0,617 t_{5 / 6-0}, 862 t_{1 / 3}\right)}{t_{5 / 6}{ }^{2}}
\end{aligned}
$$

From these expressions, it is possible to calculate a mean value of the thermal diffusivity.

Degiovanni and Laurent's model (partial moments) [12] allows to exploit all the points of thermogram. It consists in determining the thermal diffusivity from the moments of orders 0 and -1 of the thermogram defined by :

$$
M_{0}=\int_{t_{0.1}}^{t_{0.8}} \frac{T(t)}{T_{\max }} d t
$$

And

$$
M_{-1}=\int_{t_{0.1}}^{t_{0.8}} \frac{1}{t} \frac{T(t)}{T_{\max }} d t
$$

The thermal diffusivity is then obtained from the following relation:

$$
\alpha=e^{2} \frac{F\left(M_{-I}\right)}{M_{0}}
$$


With :

$$
\begin{gathered}
F\left(M_{-1}\right)=0,08548-0,314\left(0,5486-M_{-1}\right)+0,500\left(0,5486-M_{-1}\right)^{2,63} \\
\qquad \text { for } M_{-1}>0,27 \\
F\left(M_{-1}\right)=-0,08519+0,305 M_{-1} \\
\text { for } M_{-1}>0,44
\end{gathered}
$$

Yezou's model [13] supposes that the surface exchange coefficients are equals on the two sides of the parallelepiped sample, also it takes into account the irradiation time $\mathrm{t}_{0}$.

The terms of thermal diffusivity are given by:

$$
\begin{aligned}
& \alpha_{1 / 2}=\frac{e^{2}}{t_{1 / 2}+t_{0} / 2}\left[-0,4032\left(\frac{t_{1 / 2}+t_{0} / 2}{t_{5 / 6}+t_{0} / 2}\right)^{2}+0,1103\left(\frac{t_{1 / 2}+t_{0} / 2}{t_{5 / 6}+t_{0} / 2}\right)+0,2027\right] \\
& \alpha_{5 / 6}=\frac{e^{2}}{t_{5 / 6}+t_{0} / 2}\left[0,713\left(\frac{t_{1 / 2}+t_{0} / 2}{t_{5 / 6}+t_{0} / 2}\right)^{2}-1,812\left(\frac{t_{1 / 2}+t_{0} / 2}{t_{5 / 6}+{ }^{+} t_{2} / 2}\right)+1,037\right]
\end{aligned}
$$

The times $t_{i / j}$ corresponds to the fraction $i / j$ of the maximum temperature rise, and are directly deduced from the experimental thermogram.

For measuring the thermal diffusivity of granular material such as wood chips, which is not a consolidated material, the vegetable aggregates are placed in a parallelepiped frame of dimension $25 \times 25 \times 2 \mathrm{~cm}^{3}$, having a shape compatible with the measuring arrangement.

The two main faces through which the heat flow is passed, are made of copper plates $1 \mathrm{~mm}$ thick, and the four side faces are made of wood $10 \mathrm{~mm}$ thick.

The thermal conductivity of copper is very high, so with a thickness of $1 \mathrm{~mm}$, it gives a negligible thermal resistance, and therefore the heat flow is applied directly to the granular material. For the sealing of the frame after closing is ensured by several screws.

\section{Results and discussions}

The thermo-physical characteristic of wood chips has been illustrated in (tab.1). They are characterized by a low density value, and low thermal diffusivity, in addition to a high sensitivity to water vapor. This sensitivity must therefore be taken into account, especially in the study of thermal properties, since water is an excellent conductor of heat.

The density of wood chips is around $55 \mathrm{~kg} / \mathrm{m}^{3}$, which means that the arrangement is not very dense. In fact, there is a relationship between the degree of compaction and the apparent density of the wood chips. The density increases with a degree of compaction, this increase was related to the reduction of inter-particle voids.

The (fig.4) shows the influence of the degree of compaction on thermal diffusivity of wood chips. This study was carried out on different densities. The results show that the thermal diffusivity (under $\mathrm{RH} \approx 75 \%$ ) (2.87E-7 to $1.07 \mathrm{E}-7 \mathrm{~m}^{2} / \mathrm{s}$ according to the Yezou model) decrease with the degree of compaction. The same results were shown by El bouardi et al. [14] for a lightweight material "Vermex M". This decrease is explained by the progressive elimination of inter granular air of vegetable particles whose diffusivity is lower than that of air.

Moisture absorption tests in an aqueous media in (fig.3) give high mass gain values. It was therefore concluded that wood chips have a high absorbency against liquid water. Concerning the kinetics of this phenomenon of water absorption, it was observed that the vegetable particles are in a quasi-saturated state after a few minutes of immersion.

The variation of thermal diffusivity as a function of moisture content of wood chips was presented in (fig.5). The results show a fluctuation and a decrease of thermal diffusivity. Indeed, a maximum thermal diffusivity is observed for the value of water content $\mathrm{W}_{\mathrm{m}}$, which is about $21 \%$. The same phenomenon has been observed on other materials, such as expanded glass bead, pozzolana grains [15], lateritic soil-based material [16], wood-concrete composite [17]. This result can be explained by the variation of $(\rho c)$ and $\mathrm{k}$ according to the water content which is related by the equation $\alpha=\frac{k}{\rho c}$. Therefore, it is interesting to measure simultaneously and for each water content the value of the thermal conductivity and the heat volume. Taoukil et al. [8] explained this increase in thermal diffusivity from $\left(0\right.$ to $\left.\mathrm{W}_{\mathrm{m}}\right)$ by the fact that the value of thermal conductivity increases faster than heat volume $(\rho c)$, and the decrease in thermal diffusivity with mass water content from $\left(\mathrm{W}_{\mathrm{m}}\right.$ to $\left.\mathrm{W}_{\mathrm{sat}}\right)$ was explained by the fact that the value of thermal conductivity $\mathrm{k}$ increases more slowly than heat volume $(\rho c)$.

The thermal diffusivity obtained from the four models in (fig.4) and (fig.5) has been compared. It was noted that the Degiovanni and Yezou model are close to each other, while Parker's model and Degiovanni \& Laurent's model also follow the same path, although Parker used only one point which is "half-elevation", while Degiovanni \& Laurent use the whole thermogram.

In addition, the curve of temperature evolution of wood chips in dry and saturated state was shown in (fig.6). The both curves started from zero, after a certain time, they started to vary according to the state of the material. In the dry state, the temperature increase can be observed with an inflection up to a maximum in 275 seconds, and it came back to decrease rapidly due to natural convection and radiation losses. While in the saturated state of the material, the remaining temperature evolved slowly and reached its maximum after 831 seconds and then started to decrease slowly. This means that the water content influences especially, the temperature evolution in the material and prevents the diffusion of heat through the material.

Tab. 1. Thermo-physical characteristic of wood chips under $\mathrm{HR} \approx 75 \%$

\begin{tabular}{ccc}
\hline $\begin{array}{c}\text { Bulk } \\
\text { Density } \\
\left(\mathrm{kg} / \mathrm{m}^{3}\right)\end{array}$ & $\begin{array}{c}\text { Moisture Content } \\
(\%)\end{array}$ & $\begin{array}{c}\text { Thermal } \\
\text { Diffusivity } \\
.10^{-7}\left(\mathrm{~m}^{2} / \mathrm{s}\right)\end{array}$ \\
\hline 55 & 16 & 2,4 \\
\hline
\end{tabular}




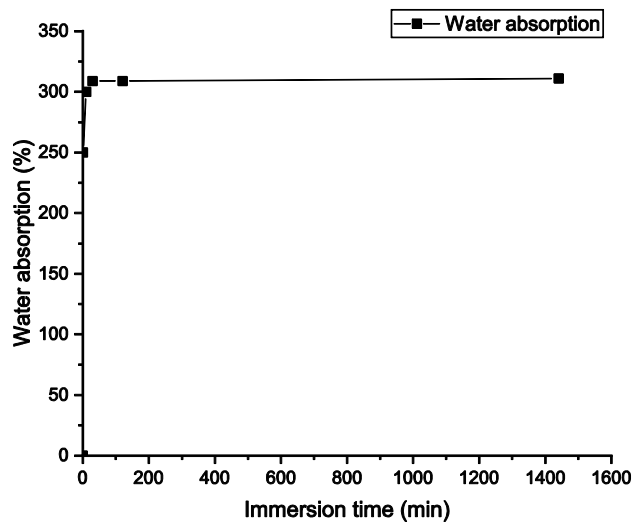

Fig. 3. Mass water absorption curve of wood chips as function of time

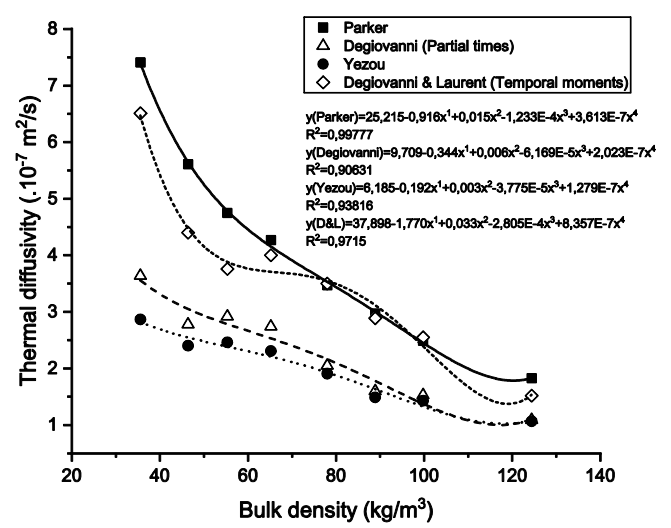

Fig. 4. Thermal diffusivity of bulk wood chips as a function of its density

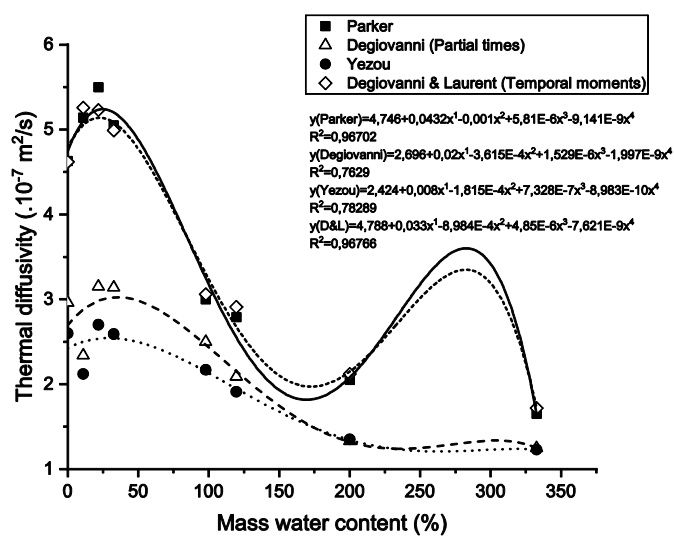

Fig. 5. Thermal diffusivity as a function of the mass water content of wood chips

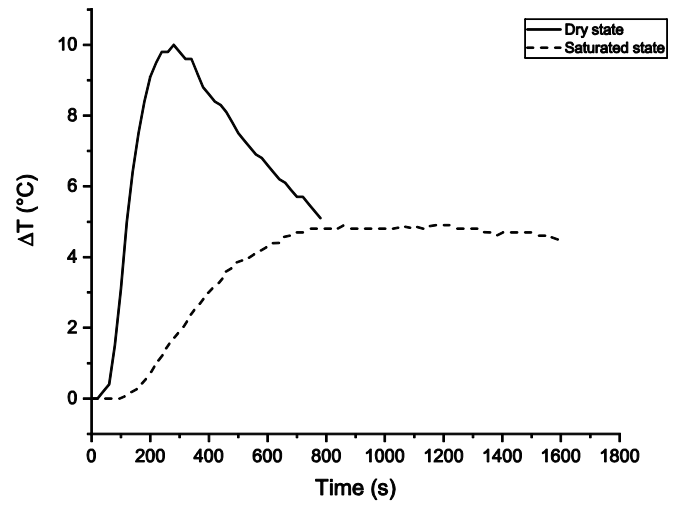

Fig. 6. The evolution of temperature of dry and saturated wood chips when subjected to a 20 s excitation flux at $\mathrm{t}=0$

\section{Conclusion}

Following the results obtained, it was found that wood chips from agro-industrial waste have a low density, of the order of $55 \mathrm{~kg} / \mathrm{m}^{3}$. Moreover, they have a significant intra-particle porosity and an important air volume located between these particles (inter-particles), due to their sizes which varies between 5 and $30 \mathrm{~mm}$. This poral distribution makes the wood chips compressible and very sensitive to water.

In this study, the influence of water content and density of wood chips on thermal diffusivity were investigated. The increase of the density of wood chips induces to a significant decrease in its thermal diffusivity, due to the decrease of voids inter particles by compaction. Also, the presence of water in the material studied, considerably influences its thermal diffusivity by slowing the speed of heat penetration through the wood chips. Besides that, during the evolution of the diffusivity as a function of water, it appears a maximum corresponds to a water content $\mathrm{W}_{\mathrm{m}}$.

The calculated thermal diffusivity values depend on the four thermogram counting models used. The difference in values obtained for each model is due to the difference between the basic assumptions used. Although the thermal diffusivity values obtained by Degiovanni and Yezou are still close to each other, the model of the latter remains the most compatible in this case. This was justified by the fact that the model uses conditions close to the experimental conditions under study: such as the parallelepiped shape of the sample, the non-negligible thermal excitation and the consideration of heat losses on the front and rear faces of the sample.

\section{Acknowledgments}

The authors should address their acknowledgments to the energetic laboratory staff members for their supports. 


\section{References}

[1] F. Asdrubali, F. D'Alessandro, et S. Schiavoni, «A review of unconventional sustainable building insulation materials », Sustain. Mater. Technol., vol. 4, p. 1-17, (2015).

[2] A. Korjenic, V. Petránek, J. Zach, et J. Hroudová, « Development and performance evaluation of natural thermal-insulation materials composed of renewable resources », Energy Build., vol. 43, no 9, p. 2518-2523, (2011).

[3] H. Binici, «Mechanical, thermal and acoustical characterizations of an insulation composite made of bio-based materials », Sustain. Cities Soc., p. 10, (2016).

[4] L. Ba et al., «Experimental Investigation of Thermal and Mechanical Properties of Clay Reinforced with Typha australis: Influence of Length and Percentage of Fibers », Waste Biomass Valorization, (2020).

[5] M. Madrid, A. Orbe, H. Carré, et Y. García, " Thermal performance of sawdust and lime-mud concrete masonry units », Constr. Build. Mater., vol. 169, p. 113-123, (2018).

[6] M. Palumbo, A. M. Lacasta, M. P. Giraldo, L. Haurie, et E. Correal, «Bio-based insulation materials and their hygrothermal performance in a building envelope system (ETICS) », Energy Build., vol. 174, p. 147-155, (2018).

[7] M. Palumbo, A. M. Lacasta, N. Holcroft, A. Shea, et P. Walker, «Determination of hygrothermal parameters of experimental and commercial bio-based insulation materials », Constr. Build. Mater., vol. 124, p. 269-275, (2016).

[8] D. Taoukil, A. El bouardi, F. Sick, A. Mimet, H. Ezbakhe, et T. Ajzoul, « Moisture content influence on the thermal conductivity and diffusivity of woodconcrete composite », Constr. Build. Mater., vol. 48, p. 104-115, (2013).

[9] O. Vololonirina, M. Coutand, et B. Perrin, " Characterization of hygrothermal properties of woodbased products - Impact of moisture content and temperature », Constr. Build. Mater., vol. 63, p. 223233, (2014).

[10] W. J. Parker, R. J. Jenkins, C. P. Butler, et G. L. Abbott, «Flash Method of Determining Thermal Diffusivity, Heat Capacity, and Thermal Conductivity », J. Appl. Phys., vol. 32, no 9, p. 16791684, (1961).

[11] A. Degiovanni, «Conductivité et diffusivité thermique des solides », Ref: TIP672WEB - « Mesures physiques », (1994).

[12] A. Degiovanni et M. Laurent, «Une nouvelle technique d'identification de la diffusivité thermique pour la méthode " flash " ", Rev. Phys. Appl., vol. 21, no 3, p. 229-237, (1986).

[13] R. Yezou, J.-C. Cubaud, Université Claude Bernard (Lyon), et Institut national des sciences appliquées de Lyon (Lyon), «Contribution à l'étude des propriétés thermophysiques des matériaux de construction cohérents et non cohérents », [s.n.], S.l., (1978).
[14] A. El bouardi, H. Ezbakhe, T. Ajzoul, V. Wittwer, et U. A. Essaadi, «Proprietés thermophysiques lors de changement de structure granulaire - compact. mesures et identifications; application aux matériaux a matrice déformable et expansés a l'air: cas de la vermiculites et polystyrène $»$, p. 5, (2005).

[15] A. El bouardi, «Etude en régime stationnaire et dynamique des propriétés thermophysiques de matériaux poreux humides non saturés utilisés en génie civil », Mohammed V, (1991).

[16] P. Meukam, Y. Jannot, A. Noumowe, et T. C. Kofane, «Thermo physical characteristics of economical building materials », Constr. Build. Mater., vol. 18, no 6, p. 437-443, (2004).

[17] D. Taoukil, A. El bouardi, T. Ajzoul, et H. Ezbakhe, "Effect of the incorporation of wood wool on thermo physical proprieties of sand mortars "), KSCE J. Civ. Eng., vol. 16, no 6, p. 1003-1010, (2012). 